\title{
How to Bend the Uranyl Cation via Crystal Engineering
}

Korey P. Carter ${ }^{\S}$, Mark Kalaj ${ }^{\S}$, Andrew Kerridge ${ }^{\dagger}$, J. August Ridenour ${ }^{\S}$, and Christopher L. Cahill*§

$\S$ Department of Chemistry, The George Washington University, $80022^{\text {nd }}$ Street, NW, Washington, D.C. 20052, United States

$\uparrow$ Department of Chemistry, Lancaster University, Bailrigg, Lancaster LA1 4YB, United Kingdom

\section{Abstract}

Bending the linear uranyl $\left(\mathrm{UO}_{2}{ }^{2+}\right)$ cation represents both a significant challenge and opportunity within the field of actinide hybrid materials. As part of related efforts to engage the nominally terminal oxo atoms of uranyl cation in non-covalent interactions, we synthesized a new uranyl complex, $\left[\mathrm{UO}_{2}\left(\mathrm{C}_{12} \mathrm{H}_{8} \mathrm{~N}_{2}\right)_{2}\left(\mathrm{C}_{7} \mathrm{H}_{2} \mathrm{Cl}_{3} \mathrm{O}_{2}\right)_{2}\right] \cdot 2 \mathrm{H}_{2} \mathrm{O}$ (complex 2), that featured both deviations from equatorial planarity and uranyl linearity from simple hydrothermal conditions. Based on this complex, we developed an approach to probe the nature and origin of uranyl bending within a family of hybrid materials, which was done via the synthesis of complexes 1-3 that display significant deviations from equatorial planarity and uranyl linearity (O-U-O bond angles between $162-164^{\circ}$ ) featuring 2,4,6trihalobenzoic acid ligands (where $\mathrm{X}=\mathrm{F}, \mathrm{Cl}$, and $\mathrm{Br}$ ) and 1,10-phenanthroline, along with nine additional 'non-bent' hybrid materials that either co-formed with the 'bent' complexes (4-6) or were prepared as part of complementary efforts to understand the mechanism(s) of uranyl bending (7-12). Complexes were characterized via single crystal X-ray diffraction, Raman, Infrared (IR), and luminescence spectroscopy, as well as via quantum chemical calculations and density-based quantum theory of atoms in molecules (QTAIM) analysis. Looking comprehensively, these results are compared with the small library of 'bent' uranyl complexes in the literature, and herein we computationally demonstrate the origin of uranyl bending and delineate the energetics behind this process. 


\section{Introduction}

Crystal engineering with the uranyl cation is an area of sustained interest within 5f hybrid materials as it presents a route to access unique structure types and unexpected properties across a range of dimensionalities (i.e. molecular complexes, coordination polymers (CPs), Metal-organic frameworks (MOFs), etc.) that are otherwise inaccessible via traditional coordination chemistry. ${ }^{1-13}$ Within the crystal engineering umbrella is supramolecular assembly, and use of this approach for producing uranyl hybrid materials necessitates a cognizance of the relationship between intra- and intermolecular interactions and resulting global structures. ${ }^{14-16}$ Judicious selection of uranyl acceptordonor pairings allows for exercising some control over the nature and directionality of non-covalent interactions within uranyl hybrid materials, which is particularly attractive as it allows for tectons and synthons to be selected for, thereby avoiding unpredictable uranyl hydrolysis products. Our group has recently focused on this problem via the hydrothermal synthesis of discrete, reproducible tectons featuring polypyridyl N-donor capping ligands in the first coordination sphere, which promote a single uranyl species with a specific coordination geometry. ${ }^{17-21}$ As part of this strategy, N-donor capping ligands are paired with halogen functionalized benzoic acids such that tecton assembly occurs by way of halogen or hydrogen bonding interactions, and moreover, this has proven valuable for systematically engaging the nominally terminal uranyl oxo groups. ${ }^{19-}$ 20

Engaging the oxo atoms of the uranyl cation is of interest within uranyl chemistry as the linear, triatomic uranyl cation $\left(\mathrm{UO}_{2}{ }^{2+}\right)$ is known for its rigid trans-dioxo stereochemistry with $\mathrm{O}=\mathrm{U}=\mathrm{O}$ angles that infrequently deviate from linearity $\left(180^{\circ}\right)$. This 
is likely a result of appreciable $5 f_{z}^{3}$ and $6 p_{z}$ character within the $\sigma$-bonding framework of the uranyl unit, ${ }^{22}$ although theoretical investigations have shown that, in the absence of polydentate equatorial ligands, the cis isomer of the uranyl cation may lay as low as 18 $\mathrm{kcal} / \mathrm{mol}$ above the stable trans isomer. ${ }^{23}$ The terminal nature of uranyl oxo atoms generally precludes binding in this dimension, with further coordination constrained to the equatorial plane,${ }^{24}$ and the robust nature of the trans uranyl unit, in contrast with its unknown cis analogue, suppresses reactivity of the uranyl cation. Multiple approaches have shown particular promise for affecting uranyl coordination chemistry and reactivity including oxo functionalization, ${ }^{25-28}$ distorting equatorial planarity, ${ }^{29-32}$ and breaking the linearity of the uranyl unit, ${ }^{33-37}$ yet all of these strategies typically require sophisticated synthetic processes and the presence of sterically bulky, complex ligands. ${ }^{38-39}$ The 'state of the science' on breaking the linearity of the uranyl unit was reviewed very recently by Hayton, ${ }^{40}$ wherein he demonstrate the nascent nature of this area of research. Complimenting this recent review are the efforts described herein, which grew out of our own group efforts to engage the oxo atoms of the uranyl cation via supramolecular interactions. During the course of a related study, ${ }^{18}$ we prepared a complex that featured both deviations from equatorial planarity and uranyl linearity from simple hydrothermal conditions. This complex is similar to the $\left[\mathrm{UO}_{2}(\text { phen })_{2} \mathrm{Cl}_{2}\right]$ material recently reported by Ikeda-Ohno and colleagues, ${ }^{41}$ yet we report herein a strategy and the building blocks for a general approach to the manipulation of the $\mathrm{O}=\mathrm{U}=\mathrm{O}$ bond angle via a combination of coordination chemistry and promoted supramolecular interactions to produce a family of materials featuring significant deviations from equatorial planarity and uranyl linearity. 
As a consequence, we describe the synthesis and characterization of three 'bent' complexes (1-3) featuring 2,4,6-trihalobenzoic acid ligands (where $\mathrm{Hal}=\mathrm{F}, \mathrm{Cl}$, and $\mathrm{Br}$ ) and 1,10-phenanthroline (phen), along with nine additional 'non-bent' hybrid materials that either co-formed with the 'bent' complexes (4-6) or were prepared as part of complementary efforts to understand the mechanism(s) of uranyl bending (7-12). Changes in the size of halogen on the benzoic acid ligands are found to increase the extent of uranyl bending and this observation has been probed comprehensively via structural, computational, and spectroscopic means. Moreover, we performed quantum chemical calculations at the density functional (DFT) level of theory along with densitybased quantum theory of atoms in molecules (QTAIM) analysis, which ultimately showed, using the 2,4,6-trifluorobenzoic acid-phen complex (1) as a representative example, that the bending of the uranyl unit has electronic origins and is energetically allowed until O-U-O angles reach approximately $162^{\circ}$. Additionally, the vibrational and luminescence spectra of complexes 1-9 were collected and demonstrated that whereas spectra are indeed affected by uranyl bending, the nuclearity of the complex and the identity of the equatorial ligands also contribute to the observed evolution in Raman, IR, and luminescence peak values.

\section{Experimental Methods}

\section{Synthesis}

All complexes discussed herein were synthesized via hydrothermal methods at autogenous pressure in a $23 \mathrm{~mL}$ Teflon-lined Parr bomb at varying oven temperatures. Complete synthetic details which yielded X-ray quality crystalline materials for 'bent' and 'non-bent' complexes 1-9 are included in the Supporting Information. 


\section{X-Ray Structure Determination}

Single crystals from the bulk sample of each bent phase were isolated based on crystal color and luminescence under a UV lamp (Figure S1, Supporting Information), and then mounted on MiTeGen micromounts. Structure determination for each of the single crystals was achieved by collecting reflections using $0.5^{\circ} \omega$ scans on a Bruker SMART diffractometer equipped with an APEX II CCD detector using MoKa $(\lambda=0.71073 \AA$ ) radiation at both $100(2)$ and $293(2) \mathrm{K}$. The data were integrated using the SAINT software package ${ }^{42}$ contained within the APEX II software suite ${ }^{43}$ and absorption corrections were applied using $S A D A B S .{ }^{44}$ Complexes 1-3 were solved via direct methods using SIR92 ${ }^{45}$ and all three complexes were refined using SHELXL-2014 ${ }^{46}$ contained within the WinGX software suite. ${ }^{47}$ In each structure, all non-hydrogen atoms were located via difference Fourier maps and refined anisotropically. Aromatic hydrogen atoms were located via difference Fourier maps, yet were placed at their idealized positions and allowed to ride on the coordinates of their parent carbon atom $\left(\left(U_{i s o}\right)\right.$ fixed at $\left.1.2 U_{e q}\right)$. Positional disorder in the planar phen moiety of $\mathbf{3}(\mathrm{C} 4, \mathrm{C} 12)$ was restrained via the ISOR command with uncertainty values of 0.005 and 0.01 , respectively. All figures were prepared with Crystal Maker. ${ }^{48}$ Data collection and refinement details for low temperature and room temperature collections of $\mathbf{1 - 3}$ are included in Tables S1 (LT) and S2 (RT) (Electronic Supporting Information, ESI), respectively.

Single crystals from non-bent phases were also isolated and mounted on MiTeGen micromounts. Similar procedures as described above were used for structure determination of 4-12 with data for 4-7, 10, and $\mathbf{1 2}$ collected at 293(2) K and for 8, 9, and 11 collected at 100(2) K. Structures for complexes 4-7 and 9-12 were solved via direct 
methods using SIR92 ${ }^{45}$ and via the Patterson Method $^{46}$ for complex 8 and all nine complexes were refined using SHELXL-2014 ${ }^{46}$ contained within the WinGX software suite. ${ }^{47}$ Similar to $\mathbf{1 - 3}$, aromatic hydrogen atoms for 4-12 were located via difference Fourier maps, yet were placed at their idealized positions and allowed to ride on the coordinates of their parent carbon atom. Complexes 4, 6, and 8 feature bridging hydroxide groups, confirmed via bond-valence summations (Tables S15-S17, ESI), and the hydrogen atoms on the hydroxide moieties in $\mathbf{4}$ and $\mathbf{6}$ were located and refined with DFIX restraints. Methyl hydrogen atoms on the bridging acetate groups in $\mathbf{8}$ were placed at their idealized positions with torsion angles based on electron density. Data collection and refinement details for 4-12 are included in Table S3 (ESI).

\section{Powder X-ray Diffraction}

Powder X-ray diffraction (PXRD) data on the bulk reaction product of complexes 1-9 (Figures S20-S28, ESI) were used to examine the purity of each sample. All data were collected on a Rigaku Miniflex $\left(\mathrm{Cu} \mathrm{K} \alpha, 2 \theta=3-60^{\circ}\right)$ and were analyzed using the Match software program. ${ }^{49}$ Initially, the bulk products of complexes 1-3, 6, 8 and 9 were found to contain multiple solid-state phases. Complex $\mathbf{1}$ was found to primarily co-form with 4 (Figure S20, Supporting Information) and complexes $\mathbf{2}$ and $\mathbf{3}$ was found to coform with $\mathbf{5}$ and $\mathbf{6}$, respectively (Figures S21 and S22, Supporting Information). Attempts to isolate complex $\mathbf{6}$ as a single phase also yielded complex $\mathbf{7}$ and a small amount of complex 8 (Figure S25, Supporting Information), the former of which could be isolated as a pure phase (Figure S26, Supporting Information). Regarding the impurities in the bulk products of $\mathbf{8}$ and $\mathbf{9}$, multiple attempts were made to identify and/or remove these phases, yet they persisted and were not identified. 


\section{Spectroscopic Characterization}

Raman and luminescence spectra for single crystals of 1-9 were collected on a Horiba LabRAM HR Evolution Spectrometer. For Raman spectra, data were collected for five seconds with ten signal accumulations over the range $600-1200 \mathrm{~cm}^{-1}$ using a $532 \mathrm{~nm}$ laser, whereas for luminescence spectra, data were collected using a $405 \mathrm{~nm}$ excitation laser over the $450-650 \mathrm{~nm}$ range.

Infrared (IR) spectra for single crystals of 1-9 were collected on a Nicolet 6700 FTIR coupled with a diamond coated ATR and MCT-A detector. Data were collected over the range $650-4000 \mathrm{~cm}^{-1}$, and 512 scans were collected for each spectrum to enhance the signal-to-noise ratio and minimize background effects.

\section{Computational Details}

Density functional theory (DFT) calculations have been performed on individual molecules using version 6.4 of the TURBOMOLE quantum chemistry software package. ${ }^{50}$ Alrichs def2-TZVP basis sets of triple-quality have been used for the $\mathrm{C}, \mathrm{H}, \mathrm{O}$, and $\mathrm{N}$ atoms, ${ }^{51}$ whereas the Alrichs def-TZVP basis set of triple-zeta quality, which incorporates a relativistic ECP comprising 60 core electrons has been used for the $\mathrm{U}$ atoms. ${ }^{52}$ Hereafter this basis set will be referred to as $\operatorname{def}(2)-T Z V P$. All simulations were performed using the B3LYP hybrid-GGA exchange-correlation functional, which has been to shown to reproduce experimental parameters of uranyl complexes with high accuracy. ${ }^{53-54}$ Analysis of resultant electron densities was performed using Bader's Quantum Theory of Atoms in Molecules (QTAIM) approach ${ }^{55}$ via version 13.11 .04 of the AIMA11 software suite. ${ }^{56}$

\section{Results}




\section{Description of Structures}

Single crystal X-ray crystallographic analyses of complexes 1-9, which feature either 2,4,6-trihalobenzoic acid or benzoic acid ligands along with the chelating $\mathrm{N}$-donor 1,10-phenanthroline revealed three 'bent' and six 'non-bent' complexes in this family of materials. Local structures are described in detail for 'bent' complexes 1-3, whereas structural aspects of 'non-bent' complexes 4-9 are described only when necessary for context and comparison. Structural details for 'non-bent' complexes are provided in the ESI.

Complex 1, $\left[\mathrm{UO}_{2}\left(\mathrm{C}_{12} \mathrm{H}_{8} \mathrm{~N}_{2}\right)_{2}\left(\mathrm{C}_{7} \mathrm{H}_{2} \mathrm{~F}_{3} \mathrm{O}_{2}\right)_{2}\right] \cdot\left(\mathrm{C}_{12} \mathrm{H}_{8} \mathrm{~N}_{2}\right)$, co-forms with the 'nonbent' complex 4, $\left[\mathrm{UO}_{2}(\mathrm{OH})\left(\mathrm{C}_{12} \mathrm{H}_{8} \mathrm{~N}_{2}\right)\left(\mathrm{C}_{7} \mathrm{H}_{2} \mathrm{~F}_{3} \mathrm{O}_{2}\right)\right]_{2}$, and crystallizes in the space group $P-1$. The asymmetric unit of $\mathbf{1}$ features one 'bent' uranyl cation that adopts dodecadeltahedron molecular geometry upon chelation by two bidentate phen molecules and coordination by two monodentate 2,4,6-trifluorobenzoic acid ligands, along with an additional neutral phen molecule in the lattice (Figure 1). U1-O bond distances to the monodentate 2,4,6-trifluorobenzoic acid ligands (O3 and O5) are 2.281(3) $\AA$ and 2.280(3) $\AA$, respectively. The two bidentate phen molecules chelate the uranyl cation almost perpendicular to one another and we note significant variance in the U-N bond distances of these two ligands. U1-N bond distances with the phen molecule in the uranyl equatorial plane (N1, N2) are 2.627(3) $\AA$ (U1-N1) and 2.599(3) $\AA$ (U1-N2), whereas U1$\mathrm{N}$ distances to the phen moiety perpendicular to the equatorial plane $(\mathrm{N} 3, \mathrm{~N} 4)$ are 2.771(3) $\AA$ (U1-N3) and 2.799(3) $\AA$ (U1-N4). We observe a similar contrast when comparing the $\angle \mathrm{N}-\mathrm{U}-\mathrm{N}$ angles for the two phen moieties with the planar phen featuring an $\angle \mathrm{N} 1-\mathrm{U} 1-\mathrm{N} 2$ of $62.88(10)^{\circ}$ and the non-planar phen displaying an $\angle \mathrm{N} 3-\mathrm{U} 1-\mathrm{N} 4$ of 
$57.98(10)^{\circ}$. The U-N and $\angle \mathrm{N}-\mathrm{U}-\mathrm{N}$ distances and angles observed in $\mathbf{1}$ represent the longest U-N bonds and smallest $\angle \mathrm{N}-\mathrm{U}-\mathrm{N}$ angle ever observed in a uranyl hybrid material according to a search of the Cambridge Structural Database (v 5.38, Nov. 2016), ${ }^{57}$ and likely drive the unusual behavior of the uranyl cation described below.
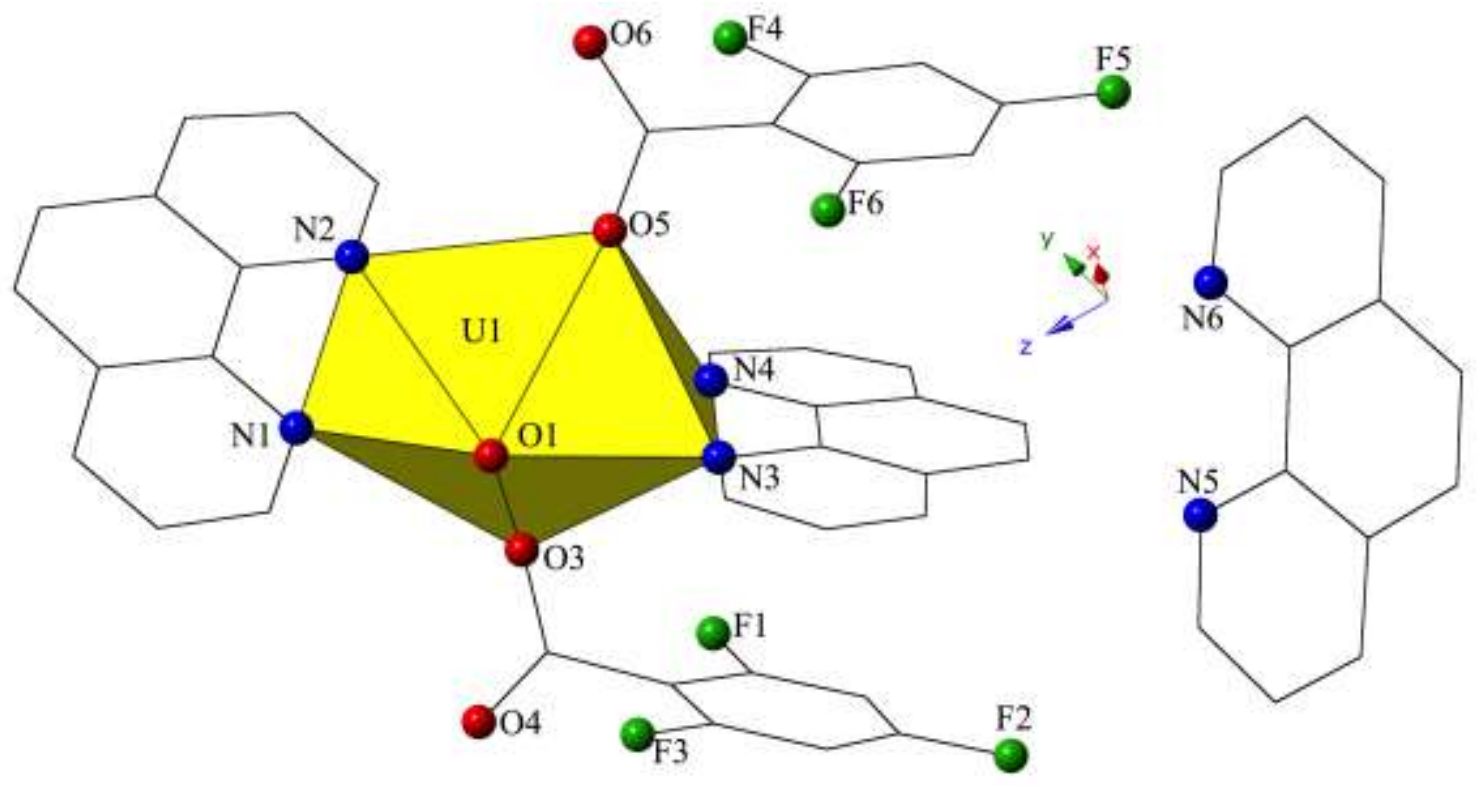

Figure 1 Polyhedral representation of local coordination geometry of 1. Yellow polyhedra represent uranium metal centers, whereas green, red, and blue spheres represent fluorine, oxygen, and nitrogen atoms, respectively. All $\mathrm{H}$ atoms have been omitted for clarity.

The breaking of equatorial planarity by one the phen molecules (N3 and N4) does not affect U1-O bond distances to oxo atoms $\mathrm{O} 1$ and $\mathrm{O} 2$, which are characteristic of uranyl materials at $1.778(3) \AA$ and $1.785(3) \AA{ }^{24}$ yet we do see a manifestation of the deviation from planarity in the $\angle \mathrm{O} 1-\mathrm{U} 1-\mathrm{O} 2$ angle, which is considerably bent away from linear at $164.93(12)^{\circ}$. A recent study from Hayton et al. surveyed uranyl bending in hybrid materials and reported that the smallest observed $\angle \mathrm{O}-\mathrm{U}-\mathrm{O}$ angles for the uranyl unit were between $166-168^{\circ} .{ }^{37}$ In their study, they highlighted three compounds made with the uranyl cation and a 12-membered macrocycle with $\angle \mathrm{O}-\mathrm{U}-\mathrm{O}$ angles between 
$161.7(5)^{\circ}$ and $164.1(3)^{\circ}$, thereby setting a new mark for uranyl bending, which has recently been matched by Ikeda-Ohno et al. ${ }^{41}$ The bending of the uranyl cation in $\mathbf{1}$ coupled with the concomitant deviation from equatorial planarity also observed is a rare combination in uranyl hybrid materials, with the $\left[\mathrm{UO}_{2} \mathrm{Cl}_{2}(\mathrm{phen})_{2}\right]$ complex characterized recently by Ikeda-Ohno et al. the only analogue to $\mathbf{1}$ found in the literature. ${ }^{41}$

Changing the benzoic acid ligand from 2,4,6-trifluorobenzoic acid to the 2,4,6trichloro analogue results in the co-formation of complex $\mathbf{2}$, $\left[\mathrm{UO}_{2}\left(\mathrm{C}_{12} \mathrm{H}_{8} \mathrm{~N}_{2}\right)_{2}\left(\mathrm{C}_{7} \mathrm{H}_{2} \mathrm{Cl}_{3} \mathrm{O}_{2}\right)_{2}\right] \cdot 2 \mathrm{H}_{2} \mathrm{O}$, and the 'non-bent' complex 5 , $\left[\mathrm{UO}_{2}\left(\mathrm{C}_{12} \mathrm{H}_{8} \mathrm{~N}_{2}\right)\left(\mathrm{C}_{7} \mathrm{H}_{2} \mathrm{Cl}_{3} \mathrm{O}_{2}\right)_{2}\right]$. Complex 2 crystallizes in the space group $P 2_{1} / n$ and features a local coordination environment nearly identical to $\mathbf{1}$, thus it will not be described in detail. Phen moieties chelate the uranyl cation in $\mathbf{2}$ almost perpendicular to one another, and similar to $\mathbf{1}$, we noted substantial differences in U-N bond distances and $\angle \mathrm{N}-\mathrm{U}-\mathrm{N}$ angles between the planar and non-planar phen molecules (Figure 2). U1-N bond distances with the planar phen molecule (N1, N2) are 2.636(4) $\AA$ and 2.582(4) $\AA$, respectively, whereas U1-N distances to the non-planar phen moiety $(\mathrm{N} 3, \mathrm{~N} 4)$ are more than $0.1 \AA$ longer than those to the planar ligand at 2.757(4) $\AA$ (U1-N3) and 2.777(4) $\AA$ (U1-N4). $\angle \mathrm{N}-\mathrm{U}-\mathrm{N}$ angles differ between the two molecules by ca. $4^{\circ}$ with the planar phen featuring an $\angle \mathrm{N} 1-\mathrm{U} 1-\mathrm{N} 2$ of $62.86(13)^{\circ}$ and the non-planar phen displaying an $\angle \mathrm{N} 3-\mathrm{U} 1-\mathrm{N} 4$ of $58.48(13)^{\circ}$. Deviations from uranyl planarity manifest in the $\angle \mathrm{O} 1-\mathrm{U} 1-\mathrm{O} 2$ angle of $\mathbf{2}$, which is bent even more than in $\mathbf{1}$, at $162.86(16)^{\circ}$ (a $2.07^{\circ}$ decrease from $\left.\mathbf{1}\right)$. 


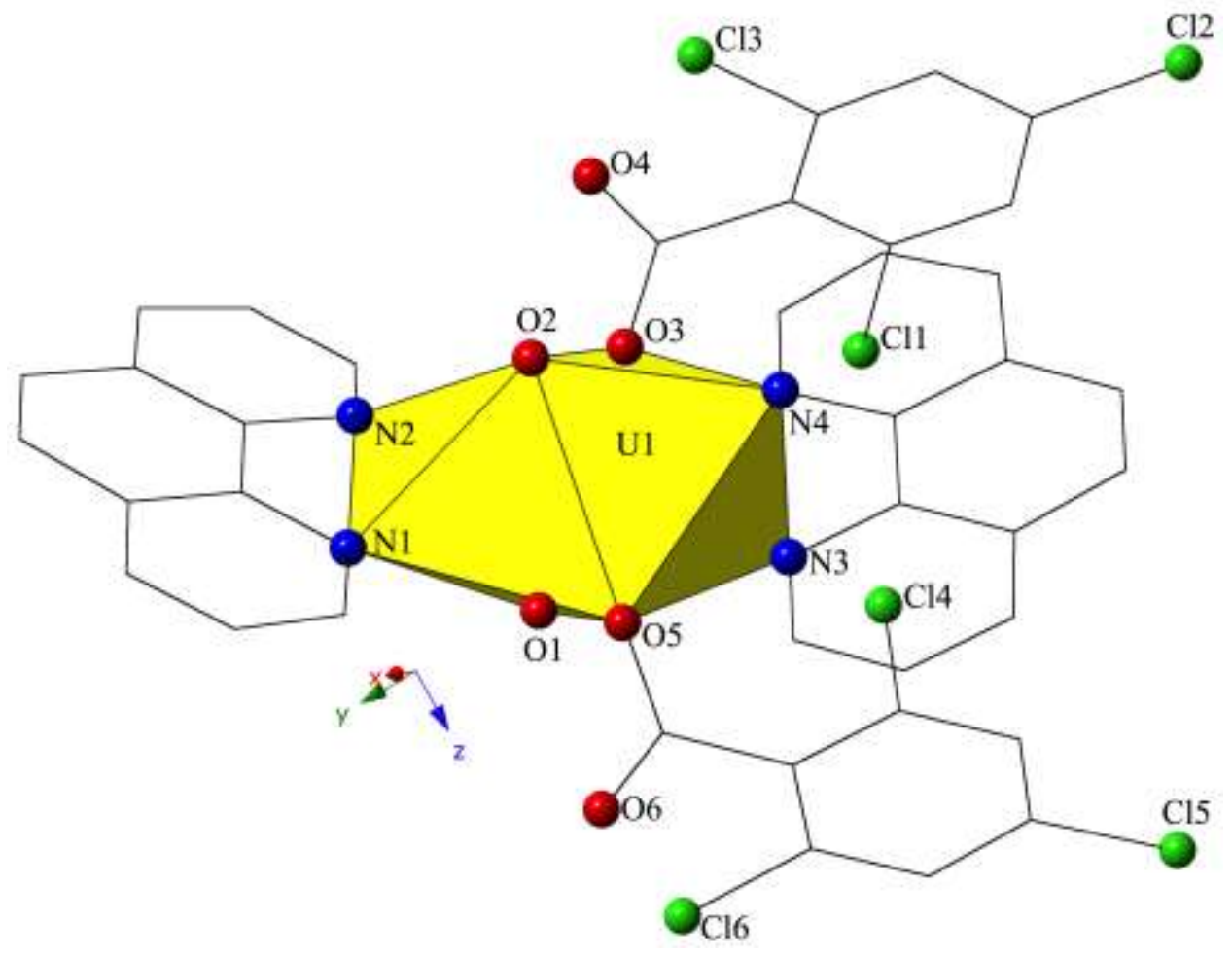

Figure 2 Polyhedral representation of local coordination geometry of 2. Lime green spheres represent chlorine atoms. Lattice water molecules have been omitted for clarity.

Switching to 2,4,6-tribromobenzoic acid as the benzoic acid ligand of choice results in the co-formation of complex $3,\left[\mathrm{UO}_{2}\left(\mathrm{C}_{12} \mathrm{H}_{8} \mathrm{~N}_{2}\right)_{2}\left(\mathrm{C}_{7} \mathrm{H}_{2} \mathrm{Br}_{3} \mathrm{O}_{2}\right)_{2}\right]$, and the 'nonbent' complex 6, $\left[\mathrm{UO}_{2}(\mathrm{OH})\left(\mathrm{C}_{12} \mathrm{H}_{8} \mathrm{~N}_{2}\right)\left(\mathrm{C}_{7} \mathrm{H}_{2} \mathrm{Br}_{3} \mathrm{O}_{2}\right)\right]_{2}$. Complex 3 crystallizes in the space group $P 2{ }_{1} / c$ and features a local coordination environment nearly identical to both $\mathbf{1}$ and 2. Phen moieties once again chelate the uranyl cation almost perpendicular to one another with U1-N bond distances to the planar phen molecule (N1, N2) at 2.609(4) $\AA$ (U1-N1) and 2.640(4) $\AA$ (U1-N2) (Figure 3). U1-N bond distances to the non-planar phen moiety are significantly longer at 2.763(4) $\AA$ (U1-N3) and 2.751(4) $\AA$ (U1-N4), and $\angle \mathrm{N}-\mathrm{U}-\mathrm{N}$ angles differ between the planar and non-planar phen molecules by ca. $4^{\circ}$ at $62.83(13)^{\circ}$ $(\angle \mathrm{N} 1-\mathrm{U} 1-\mathrm{N} 2)$ and $58.95(13)^{\circ}(\angle \mathrm{N} 3-\mathrm{U} 1-\mathrm{N} 4)$, respectively. These deviations from uranyl planarity once again manifest in bending of the O1-U1-O2 unit, similar to $\mathbf{1}$ and $\mathbf{2}$, and 
we note an additional deviation from linearity of the uranyl unit in $\mathbf{3}$ as we switch to benzoic acid units featuring larger halogen atoms with the $\angle \mathrm{O} 1-\mathrm{U} 1-\mathrm{O} 2$ angle at $162.18(16)^{\circ}$, a $2.75^{\circ}$ decrease from 1 and a $0.68^{\circ}$ decrease from 2 . The O-U-O angle in $\mathbf{3}$ is comparable to the smallest values reported in the literature by Hayton $^{37}$ and IkedaOhno, ${ }^{41}$ and represents the most significant uranyl bending we observe in this family of complexes.

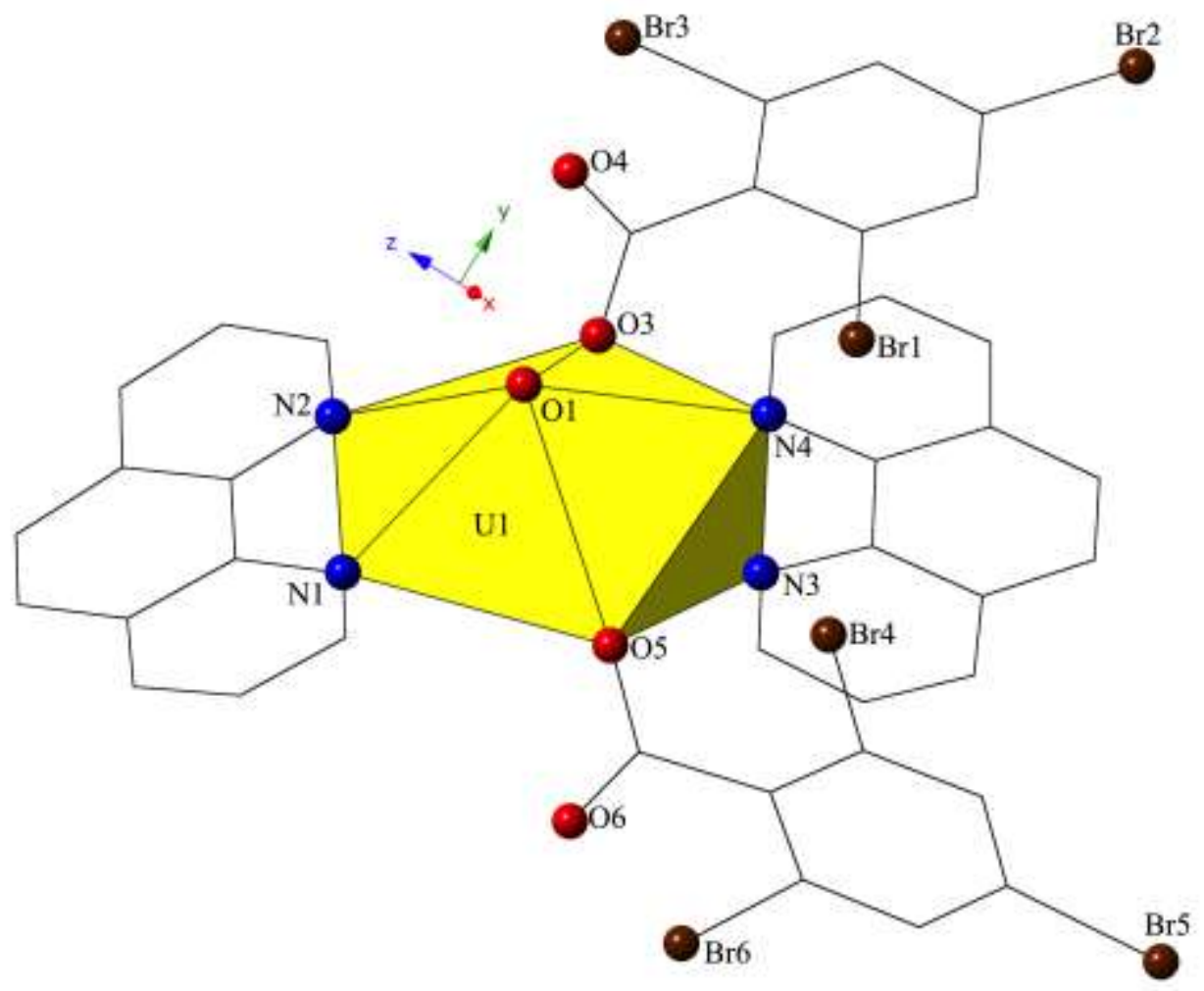

Figure 3 Polyhedral representation of local coordination geometry of $\mathbf{3}$. Brown spheres represent bromine atoms.

\section{Discussion}

As 'bent' complexes (1-3) were consistently observed to co-form with 'non-bent' complexes (4-6), the latter were structurally analyzed, along with 'non-bent' 2,4,6tribromobenzoic-phen minor phase (complex 7) and benzoic acid phases (complexes 8 and 9) (Figure 4, Figures S5-S7, Supporting Information), to assess the influence of both 
benzoic acid and phen ligands, along with intramolecular interaction strength, on driving deviations from equatorial planarity and uranyl linearity.
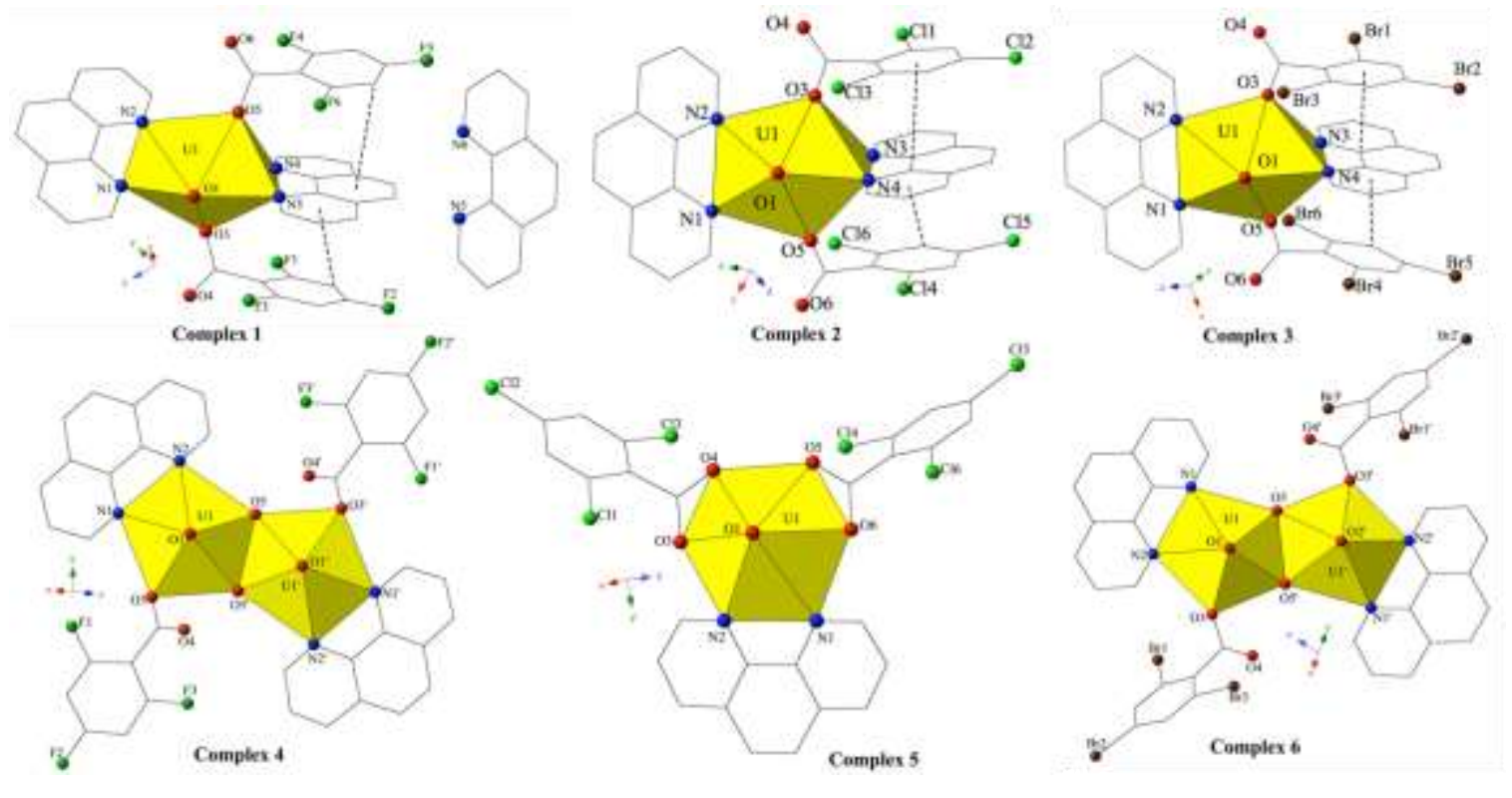

Figure 4 Summary of observed local coordination environments for 'bent' and 'nonbent' complexes 1-6. Intramolecular offset $\pi-\pi$ stacking interactions that likely stabilize non-planar phen molecules in 'bent' complexes are shown.

Comparing the 2,4,6-trifluorobenzoic acid complexes $\mathbf{1}$ and $\mathbf{4}$, we note that complex 1 is a 'bent' 1:2 complex with respect to the uranyl cation and both ligands, whereas complex 4 is a 'non-bent' 1:1 uranyl dimer (Figure 4). We observe an identical relationship for with 2,4,6-tribromobenzoic acid complexes $\mathbf{3}$ and $\mathbf{6}$, and subtler differences between 'bent' and 'non-bent' 2,4,6-trichlorobenzoic acid complexes $\mathbf{2}$ and $\mathbf{5}$, which are both monomers and feature only changes in the uranyl:phen ratio (1:2 and 1:1 for the 'bent' and 'non-bent' complexes, respectively) (Figure 4). In all three 'bent' complexes we also note offset, intramolecular $\pi$-interactions ${ }^{58}$ between $2,4,6$ trihalobenzoic acid ligands and the non-planar phen moieties at distances of approximately $3.5 \AA$ (Figure 4). The nature of these contacts varies slightly from the 
intermolecular $\pi$-interactions described by Ikeda-Ohno et al. in their 'bent' $\left.\left[\mathrm{UO}_{2} \mathrm{Cl}_{2} \text { (phen }\right)_{2}\right]$ uranyl complex, which features two unique sets of $\pi$-interactions, one between planar phen molecules and the other between non-planar phen ligands. ${ }^{41}$ The role of the intramolecular $\pi$-interactions in $\mathbf{1 - 3}$ is likely to stabilize the non-planar phen molecules, and subsequently the overall 'bent' complexes. Additional stabilization of the non-planar phen molecules is likely necessary as the U-N distances and $\angle \mathrm{N}-\mathrm{U}-\mathrm{N}$ angles for the non-planar phen moieties in $\mathbf{1 - 3}$ are significantly longer and smaller (respectively) than have previously been observed in any uranyl hybrid material featuring phen. ${ }^{11,17}$ In fact, there are only two previous examples of uranyl-phen complexes displaying a U:phen ratio other than 1:1: the rhombohedral $\left[\mathrm{UO}_{2}(\mathrm{phen})_{3}\right][\mathrm{OTf}]_{2}$ from Berthet and colleagues ${ }^{30}$ and the recently synthesized $\left.\left[\mathrm{UO}_{2} \mathrm{Cl}_{2} \text { (phen }\right)_{2}\right]$ from Ikeda-Ohno et al. ${ }^{41}$

A closer look at the synthetic conditions that produced 'bent' phases with 2,4,6trifluoro- and tribromobenzoic acids (complexes $\mathbf{1}$ and $\mathbf{3}$ ), indicates that single crystals of the 'bent' phases were only found when the uranyl to phen molar ratio was increased to at least 1:3 (at molar ratios of $<1: 3$ only 'non-bent' phases (complexes 4 and $\mathbf{6}$ ) were produced). In contrast, with 2,4,6-trichlorobenzoic acid the 'bent' phase was found to only be uranyl starting salt dependent. From a structural and synthetic perspective, these observations suggest that the benzoic acid ligands featured in 1-3 play an ancillary role in driving uranyl bending as deviations from linearity are noted for varied conditions, wherein the uranyl-benzoic acid ligand molar ratio is kept constant. The role of phen in driving uranyl bending and breaking equatorial planarity however, is most clearly illustrated by comparing complexes $\mathbf{2}$ and 5 (Figure 5). In the evolution between the 'bent' and 'non-bent' complexes highlighted in Figure 5, we can see the unique role of 
the non-planar phen, which fits into the 'pocket' created by the change of the 2,4,6trichlorobenzoic acid coordination modes (from bidentate in $\mathbf{5}$ to monodentate in 2). By chelating the uranyl cation beyond the equatorial plane, phen significantly restricts coordination geometry around the uranium metal center, likely yielding the unique dodecadeltahedron molecular geometry observed in 1-3 and the concomitant bending of the uranyl cation (more on this below).
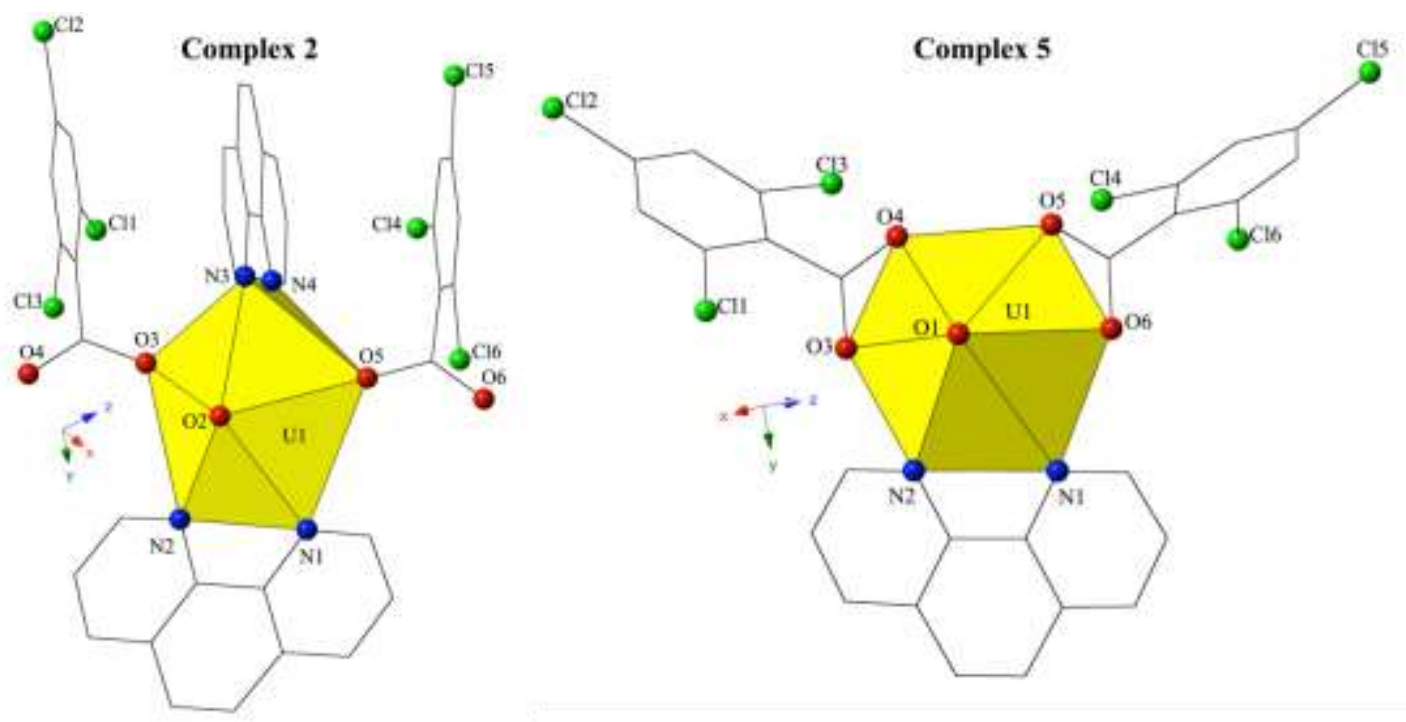

Figure 5 Observed local coordination environments for 'bent' and 'non-bent' $\mathrm{UO}_{2}-2,4,6$ trichlorobenzoic-phen complexes $\mathbf{2}$ and $\mathbf{5}$ highlighting structural differences between two complexes.

To understand more about uranyl bending we synthesized complexes with benzoic acid and phen (complexes $\mathbf{8}$ and 9, Figures S6 and S7, Supporting Information), yet only observed 'non-bent' complexes with either $2: 1$ or 1:1 stoichiometry. Analogous efforts with 2,4,6-trichlorobenzoic acid and both 2,2'-bipyridine and 2,2'-bipyridineN,N'-dioxide, using the same synthetic conditions that yielded all three 'bent' complexes (ESI), only produced 1:1 stoichiometry 'non-bent' complexes as well (with respect to U and phen) (complexes 10 and 11, Figures S8 and S9, Supporting Information), likely due 
to limits in observed $\angle \mathrm{N}-\mathrm{U}-\mathrm{N}$ angles for both chelating ligands. The importance of the 2,4,6-trihalobenzoic acids for yielding 'bent' complexes was further explored via synthesis with 2,3,5-trichlorobenzoic acid and phen. Even at molar ratios of 1:2:5 (UO2:235triClBA:phen), only a 'non-bent' 1:1 stoichiometry complex was observed (Figure S10, Supporting Information), and this observation hints at the importance of the ' $\pi$-pocket' of 1-3 highlighted in Figure 4. The intramolecular $\pi$-interactions between 2,4,6-trihalobenzoic acid ligands and non-planar phen molecules in $\mathbf{1 - 3}$ likely facilitate the formation of these 'bent' complexes, and this supramolecular motif cannot be repeated upon modification of the halogen positions on the benzoic acid ligands, perhaps due to a change in electron density distribution or sterics.

\section{Computational Results}

In an effort to understand the deviations from equatorial planarity and uranyl linearity highlighted thus far, we turned to density functional theory (DFT) calculations and quantum theory of atoms in molecules (QTAIM) analysis to probe the results detailed above. Initial DFT calculations on individual molecules representing complexes 1-3 and the simulated 2,4,6-triiodobenzoic acid analogue showed pronounced bending of the uranyl unit, yet deviations from linearity were found to be relatively independent of the halide species, in contrast to experiment (Table S4, Supporting Information). The B3LYP/def(2)TZVP model chemistry was found to simulate U-oxo and U-O(equatorial) bond lengths extremely well, particularly for $\mathrm{X}=\mathrm{F}$ and $\mathrm{Cl}$, but $\mathrm{O}-\mathrm{H}$ bond lengths were significantly underestimated and U-N bond lengths were significantly overestimated (Table S4, Supporting Information). U-N bond lengths were then constrained at experimental values and this led to a better reproduction of the uranyl bend, and its 
observed halide dependence (Table 1). Whereas calculations using this model chemistry do underestimate uranyl bending when $\mathrm{X}=\mathrm{F}$, there is a clear trend as the halide group is descended (Table 1). A consequence of this constraint, however, is that other structural metrics compare less favorably to experiment.

Table 1 Selected structural parameters of complexes 1-3. All calculations performed using the B3LYO/def(2)TZVP mode chemistry. * UN bonds were constrained to the experimental values.

\begin{tabular}{|c|c|c|c|c|c|c|}
\hline $\mathbf{X}$ & & $\begin{array}{c}\text { U-oxo } \\
(\AA)\end{array}$ & $\begin{array}{c}\text { OUO bend } \\
\left({ }^{\circ}\right)\end{array}$ & O-H (̊̊) & U-O eq $(\AA)$ & $\mathbf{U}-\mathbf{N}(\stackrel{\AA}{)})$ \\
\hline \multirow[t]{3}{*}{$\mathrm{F}$} & Exp & 1.781 & 164.94 & 2.401 & 2.281 & $2.613,2.780$ \\
\hline & Calc & 1.780 & 165.62 & 2.286 & 2.279 & $2.695,2.907$ \\
\hline & Calc* & 1.786 & 164.11 & 2.239 & 2.292 & $\mathrm{n} / \mathrm{a}$ \\
\hline \multirow[t]{3}{*}{$\mathrm{Cl}$} & Exp & 1.774 & 162.87 & 2.360 & 2.282 & $2.665,2.767$ \\
\hline & Calc & 1.779 & 165.26 & 2.283 & 2.287 & $2.700,2.897$ \\
\hline & Calc* & 1.785 & 163.02 & 2.213 & 2.309 & $\mathrm{n} / \mathrm{a}$ \\
\hline \multirow[t]{3}{*}{$\mathrm{Br}$} & Exp & 1.778 & 162.18 & 2.317 & 2.272 & $2.625,2.758$ \\
\hline & Calc & 1.778 & 165.25 & 2.278 & 2.293 & $2.703,2.890$ \\
\hline & Calc* & 1.784 & 162.24 & 2.203 & 2.315 & $\mathrm{n} / \mathrm{a}$ \\
\hline
\end{tabular}

QTAIM analysis on 1-3 using B3LYP/def(2)-TZVP derived densities indicate that values of the electron density at the U-oxo bond critical point, $\rho_{\mathrm{BCP}}$, are significantly reduced in comparison to the free uranyl cation, suggestive of a weakening of the covalent character of the U-oxo bonds comparable in magnitude to that associated with cyano/isocyanate complexation, ${ }^{59-61}$ with energy densities $(H)$ exhibiting the same behavior (Table S5, Supporting Information). An interesting, albeit weak, trend can be observed, namely an increase in the magnitudes of $\rho_{\mathrm{BCP}}, H$, and the bond ellipticity, $\varepsilon$, as the halide becomes larger (Table S5, Supporting Information). This is indicative of increasing U-oxo bond covalency as the halide group is descended, along with a slight deviation from pure triple bond character (evidenced by $\varepsilon>0$ ). As an increase in 
covalent character would be expected to lead to bond stabilization, QTAIM metrics were assessed again after fixing U-N bond lengths (consistent with the DFT simulations described above). When U-N bond distances are constrained, the same weak trend is seen that suggests increased bond covalency as the halide group is descended (Table 2, S5, Supperting Information), commensurate with a slight shortening of the U-oxo bond (see Table 1). Interestingly $\varepsilon$ is more pronounced when the U-N bonds are constrained to experimental values, signifying that the proximity of the nitrogen and uranium centers drives this phenomenon. Deviation of $\varepsilon$ from zero is symptomatic of some difference between the two U-oxo $\pi$-bonds (which are equivalent for the free uranyl ion) and this deviation becomes more pronounced as the uranyl unit becomes more bent (Table 2). From a structural perspective, the nitrogens of the planar phen might be expected to be best placed to affect a difference in the $\pi$-bonds, since they are able to directly interact with the uranium $5 \mathrm{f}$ and $6 \mathrm{~d}$ shells, and if these nitrogens were to preferentially weaken one $\pi$-bond, this would presumably soften the U-O interaction with respect to bending.

Table 2 Topological properties of the U-oxo bonds in 1-3, evaluated using B3LYP/def(2)-TZVP derived densities. * UN bonds were constrained to the experimental values.

\begin{tabular}{ccccc}
\hline $\mathbf{X}$ & $\boldsymbol{\rho}_{\mathbf{B C P}}\left(\mathbf{U}, \mathbf{O}_{\mathbf{y l}}\right)$ & $\nabla^{\mathbf{2}} \boldsymbol{\rho}_{\mathbf{B C P}}\left(\mathbf{U}, \mathbf{O}_{\mathbf{y l}}\right)$ & $\boldsymbol{H}_{\mathbf{B C P}}\left(\mathbf{U}, \mathbf{O}_{\mathbf{y l}}\right)$ & $\boldsymbol{\varepsilon}\left(\mathbf{U}, \mathbf{O}_{\mathbf{y l}}\right)$ \\
\hline free $\left[\mathrm{UO}_{2}\right]^{2+}$ & 0.366 & 0.271 & -0.395 & 0 \\
\hline $\mathrm{F}$ & 0.297 & 0.357 & -0.257 & 0.011 \\
$\mathrm{~F}^{*}$ & 0.293 & 0.362 & -0.250 & 0.019 \\
\hline $\mathrm{Cl}$ & 0.298 & 0.357 & -0.258 & 0.012 \\
$\mathrm{Cl}^{*}$ & 0.293 & 0.363 & -0.250 & 0.022 \\
\hline $\mathrm{Br}$ & 0.299 & 0.357 & -0.259 & 0.013 \\
$\mathrm{Br}^{*}$ & 0.294 & 0.363 & -0.251 & 0.024 \\
\hline
\end{tabular}

Analysis of the integrated properties of the U-oxo bonds in 1-3 reveals essentially no dependency on the degree of bond bending, with any variation commensurate with the 
slight elongation of the bond when the UN bonds are constrained, which makes a mechanism based on chemical interactions with the nitrogens of the planar phen (as proposed above) unlikely (Table S6, Supporting Information). In fact, topological analysis of the UN interaction data did not yield any variation which might account for the observed uranyl bending (Table S7, Supporting Information), suggesting that perhaps the nitrogens of the non-planar phen impact the $\mathrm{U}$-oxo bond electrostatically. If this were the case, the effect of those nitrogens would be to redistribute electronic charge from one U-oxo $\pi$-bond onto the far side of the uranyl unit, enhancing the bonding interaction on the far side of the uranyl while simultaneously depleting the interaction on the near side, leading to the bending observed experimentally, and nitrogen charges for 1-3 are highlighted in Table 3. For the non-planar nitrogens, these can be compared to the U-N separations (see Table S8, Supporting Information), showing that substantial electrostatic repulsion would be expected between the non-planar nitrogens and the electron charge accumulated in the U-oxo bond. This repulsion increases as the halides are descended, commensurate with an increase in bond ellipticity and the increased bending.

Table 3 QTAIM-derived charges of the planar and non-planar nitrogen atoms in 1-3, evaluated using B3LYP/def(2)-TZVP derived densities.

\begin{tabular}{ccc}
\hline $\mathbf{X}$ & $\mathbf{Q}\left(\mathbf{N}_{\mathbf{p}}\right)$ (a.u.) & $\mathbf{Q}\left(\mathbf{N}_{\mathbf{n p}}\right)$ (a.u.) \\
\hline $\mathrm{F}$ & -1.17 & -1.15 \\
$\mathrm{Cl}$ & -1.18 & -1.15 \\
$\mathrm{Br}$ & -1.17 & -1.15 \\
\hline
\end{tabular}

To investigate the electrostatic origins of uranyl bending further, the electronic structure of a free uranyl molecule with a geometry bent to reflect that calculated for the fluorinated complex $\mathbf{1}\left(164.11^{\circ}\right)$ was evaluated in the absence and presence of -1.15 a.u. negative charges at the non-planar nitrogen positions. Figure 6 shows the difference in 
electronic density between the two, showing a clear redistribution of electron charge away from the point charges. Evaluating the ellipticity parameter, $\varepsilon$ (see Table 2) reveals that although the ellipticity is non-zero $(\varepsilon=0.011)$ for free uranyl in a bent configuration, it becomes significantly more pronounced $(\varepsilon=0.048)$ in the presence of the non-planar nitrogen charges, supporting our interpretation of the data for the full complexes.

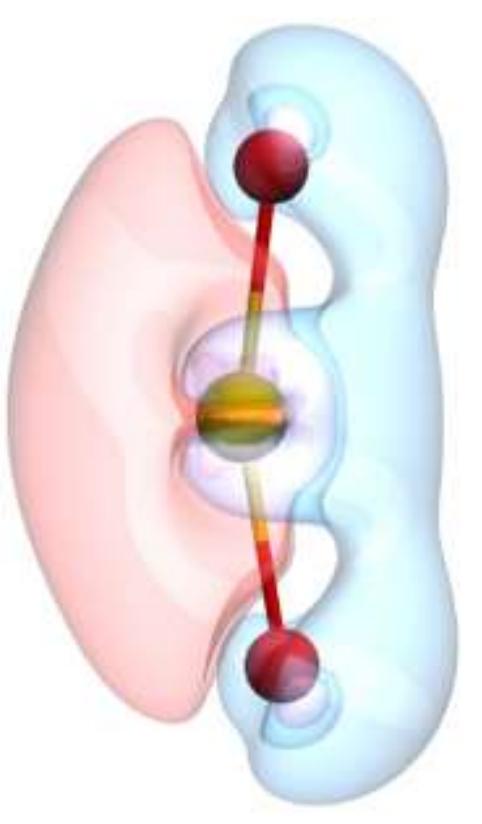

Figure 6 Electron density difference obtained when comparing the electronic structures of a bent uranyl molecule in the presence and absence of point charges at non-planar nitrogen positions. The red isosurface indicates charge depletion in the presence of the point charges and the blue surface indicates charge accumulation.

Finally, the energies of the complexes in which the U-N bond lengths are fixed are compared to those when the uranyl unit is forced to be linear in Table S9 (ESI). It should be noted that there are some uncertainties in these values due to the constraint imposed: the linearly constrained energies are upper bounds since they do not allow relaxation of the U-oxo bond lengths. However, a trend emerges of increased relative stability of the bent configuration, commensurate with an increased bend angle as the 
halides are descended. Using complex 1 as an example $(\mathrm{X}=\mathrm{F})$, the potential energy surface as a function of uranyl bend angle was calculated (Figure 7). The potential energy surface is quite flat around the minima, which may be due to the lack of crystal packing effects in the simulations, yet we have found both experimentally and computationally that as the uranyl unit deviates from linearity, the axially oriented non-planar phen ligand is able to more closely coordinate the uranium center, thereby stabilizing the complex. This phenomenon applies until ca. $162^{\circ}$, wherein variation in U-N bond lengths reduces and further bending of the uranyl unit becomes increasingly energetically unfavorable, thereby indicating that there is likely a limit to uranyl bending via coordination chemistry routes (Figure 7). 
(a)

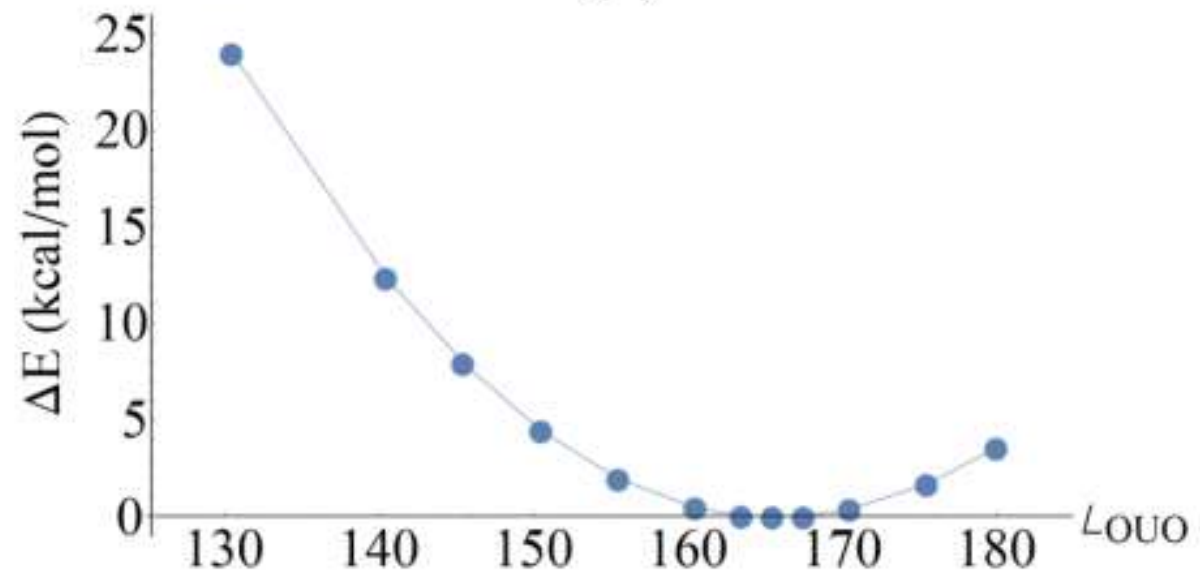

(b)

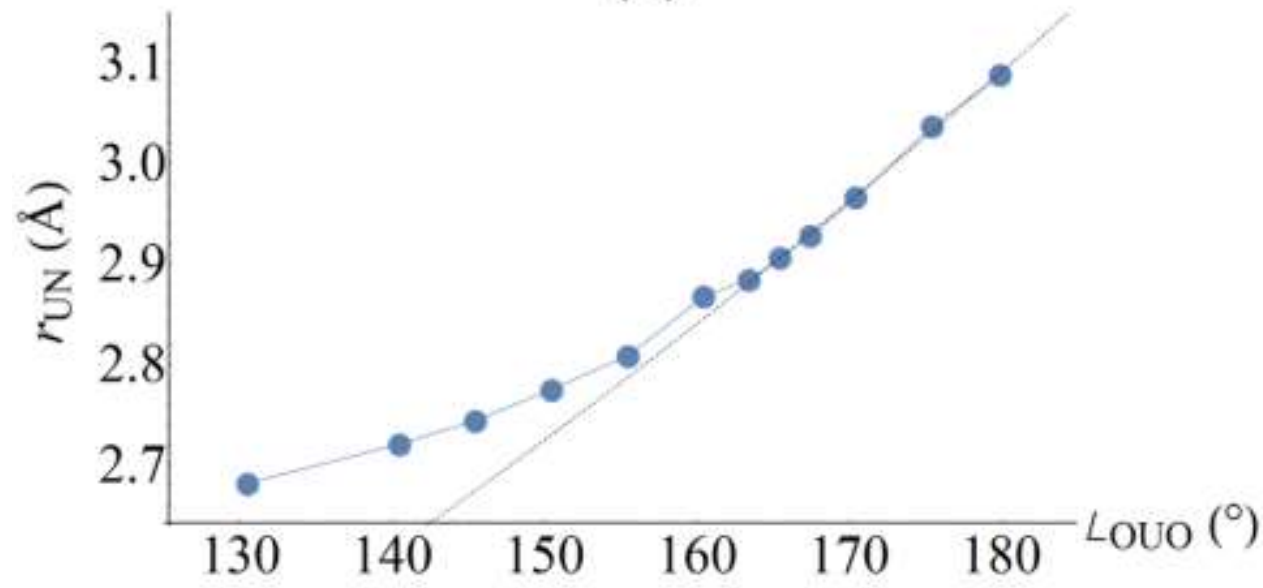

Figure 7 a) Potential energy surface associated with bending of the uranyl unit and b) variation in $\mathrm{U}-\mathrm{N}$ bond length of non-planar phen ligands in complex $\mathbf{1}$ $\left[\mathrm{UO}_{2}\left(\mathrm{C}_{12} \mathrm{H}_{8} \mathrm{~N}_{2}\right)_{2}\left(\mathrm{C}_{7} \mathrm{H}_{2} \mathrm{~F}_{3} \mathrm{O}_{2}\right)_{2}\right]$.

\section{Vibrational and Luminescence Spectroscopy}

In an effort to better understand manifestations of bending the uranyl cation, we explored the vibrational and luminescent properties of 'bent' complexes 1-3 and 'nonbent' complexes 4-9 as these techniques have proven useful for probing the nature and relative strengths of $\mathrm{U}=\mathrm{O}$ bonds. The uranyl cation is known to feature three characteristic vibrational modes: a symmetric stretching mode $\left(v_{1}, 860-880 \mathrm{~cm}^{-1}\right.$, Raman 
active), a bending mode $\left(v_{2}, 200-210 \mathrm{~cm}^{-1}\right.$, infrared active), and an asymmetric stretching mode $\left(v_{3}, 930-960 \mathrm{~cm}^{-1}\right.$, infrared active), ${ }^{62-64}$ and as $v_{2}$ stretches fall well below the detection limits of most instrumentation, we focus on the $v_{1}$ and $v_{3}$ characteristic stretches of the uranyl cation.

Looking first at the Raman spectra of 'bent' complexes 1-3, the $v_{1}$ symmetric stretch is the most prominent signal in each spectrum at $816 \mathrm{~cm}^{-1}, 844 \mathrm{~cm}^{-1}$, and $839 \mathrm{~cm}^{-}$ ${ }^{1}$, respectively (Table 4, Figure S11, Supporting Information). These results may seem counterintuitive (at first) as 2,4,6-trifluorobenzoic acid is an electron withdrawing benzoic acid ligand, and $\mathbf{1}$ features the least 'bent' uranyl unit of complexes 1-3, yet $\mathbf{1}$ does feature the longest U-oxo bond distances, which are indicators of 'weaker' $\mathrm{U}=\mathrm{O}$ bonds. Further, the electron withdrawing nature of 2,4,6-trifluorobenzoic acid, in contrast to the (weakly) electron donating character of 2,4,6-trichlorobenzoic and 2,4,6tribromobenzoic acid, does not counteract the $\mathrm{U}=\mathrm{O}$ bond effects of the non-planar phen molecules, which likely increase the ionic interaction between the uranium center and the oxo atoms by increasing electron density transferred from non-planar ligands into the $\pi^{*}$ antibonding orbitals of the uranyl cation. ${ }^{22,53-54,65}$ Comparing the $v_{1}$ symmetric stretch frequencies of 1-3 with their non-bent analogues 4-7, we note redshifts between 'bent' and 'non-bent' phases, independent of 2,4,6-trihalobenzoic acid ligand (Table 4, Figures S12 and S13, Supporting Information). The magnitude of the redshifts between 'bent' and 'non-bent' complexes are mostly small $\left(<5 \mathrm{~cm}^{-1}\right)$, with the exception of 2,4,6trifluorobenzoic acid complexes $\mathbf{1}$ and $\mathbf{4}$ and 2,4,6-tribromobenzoic acid complexes $\mathbf{3}$ and 7. Based on only structural changes from 'bent' to 'non-bent' phases one would anticipate that redshift magnitudes would be similar for 2,4,6-trifluorobenzoic acid 
complexes $\mathbf{1}$ and $\mathbf{4}$ and 2,4,6-tribromobenzoic acid complexes $\mathbf{3}$ and $\mathbf{6}$ ('bent' complexes and 'non-bent' uranyl dimers), and comparable for 2,4,6-trichlorobenzoic acid complexes 2 and $\mathbf{5}$ and 2,4,6-tribromobenzoic acid complexes $\mathbf{3}$ and $\mathbf{7}$ ('bent' complexes and 'nonbent' uranyl monomers), yet the opposite is shown to be true (Table 4). These observations confirm findings from our group and Hayton et al., ${ }^{18,21,37}$ which have demonstrated that the identity of equatorial ligands has a greater effect on Raman frequencies, than modifying the O-U-O angle of the uranyl cation or changing uranyl nuclearity.

Table 4 Comparison of $v_{1}$ Symmetric Stretch and $v_{3}$ Asymmetric Stretch Values in Bent and Non-Bent Complexes 1-9

\begin{tabular}{|c|c|c|c|c|}
\hline Complex & $\begin{array}{c}V_{1} \\
\left(\mathrm{~cm}^{-1}\right)\end{array}$ & $\begin{array}{c}v_{3} \\
\left(\mathbf{c m}^{-1}\right)\end{array}$ & $\begin{array}{l}\text { Bent/Non- } \\
\text { Bent }\end{array}$ & $\begin{array}{l}\text { Benzoic } \\
\text { Acid } \\
\text { Ligand }\end{array}$ \\
\hline $\mathrm{UO}_{2}{ }^{2+}(\mathrm{aq})$ & $\begin{array}{l}860- \\
880^{64}\end{array}$ & $\begin{array}{l}930- \\
960^{64}\end{array}$ & & \\
\hline $\begin{array}{l}{\left[\mathrm{UO}_{2}\left(\mathrm{C}_{12} \mathrm{H}_{8} \mathrm{~N}_{2}\right)_{2}\right.} \\
\left.\left(\mathrm{C}_{7} \mathrm{H}_{2} \mathrm{~F}_{3} \mathrm{O}_{2}\right)_{2}\right] \bullet\left(\mathrm{C}_{12} \mathrm{H}_{8} \mathrm{~N}_{2}\right)(\mathbf{1})\end{array}$ & 816 & 900 & Bent & 246triFBA \\
\hline $\begin{array}{l}{\left[\mathrm{UO}_{2}\left(\mathrm{C}_{12} \mathrm{H}_{8} \mathrm{~N}_{2}\right)_{2}\right.} \\
\left.\left(\mathrm{C}_{7} \mathrm{H}_{2} \mathrm{Cl}_{3} \mathrm{O}_{2}\right)_{2}\right] \cdot 2 \mathrm{H}_{2} \mathrm{O}(\mathbf{2})\end{array}$ & 844 & 888.5 & Bent & 246triClBA \\
\hline $\begin{array}{l}{\left[\mathrm{UO}_{2}\left(\mathrm{C}_{12} \mathrm{H}_{8} \mathrm{~N}_{2}\right)_{2}\right.} \\
\left.\left(\mathrm{C}_{7} \mathrm{H}_{2} \mathrm{Br}_{3} \mathrm{O}_{2}\right)_{2}\right](3)\end{array}$ & 839 & 886.5 & Bent & 246triBrBA \\
\hline $\begin{array}{l}{\left[\mathrm{UO}_{2}(\mathrm{OH})\left(\mathrm{C}_{12} \mathrm{H}_{8} \mathrm{~N}_{2}\right)\right.} \\
\left.\left(\mathrm{C}_{7} \mathrm{H}_{2} \mathrm{~F}_{3} \mathrm{O}_{2}\right)\right]_{2}(\mathbf{4})\end{array}$ & 843.5 & 918.5 & Non-Bent & 246triFBA \\
\hline $\begin{array}{l}{\left[\mathrm{UO}_{2}\left(\mathrm{C}_{12} \mathrm{H}_{8} \mathrm{~N}_{2}\right)\right.} \\
\left.\left(\mathrm{C}_{7} \mathrm{H}_{2} \mathrm{Cl}_{3} \mathrm{O}_{2}\right)_{2}\right](\mathbf{5})\end{array}$ & 847 & 924 & Non-Bent & 246triClBA \\
\hline $\begin{array}{l}{\left[\mathrm{UO}_{2}(\mathrm{OH})\left(\mathrm{C}_{12} \mathrm{H}_{8} \mathrm{~N}_{2}\right)\right.} \\
\left.\left(\mathrm{C}_{7} \mathrm{H}_{2} \mathrm{Br}_{3} \mathrm{O}_{2}\right)\right]_{2}(\mathbf{6})\end{array}$ & 841 & 909 & Non-Bent & 246triBrBA \\
\hline $\begin{array}{l}{\left[\mathrm{UO}_{2}\left(\mathrm{C}_{12} \mathrm{H}_{8} \mathrm{~N}_{2}\right)\right.} \\
\left.\left(\mathrm{C}_{7} \mathrm{H}_{2} \mathrm{Br}_{3} \mathrm{O}_{2}\right)_{2}\right]_{2}(7)\end{array}$ & 874.5 & 937 & Non-Bent & 246triBrBA \\
\hline $\begin{array}{l}{\left[\left(\mathrm{UO}_{2}\right)_{2}(\mathrm{OH})(\mathrm{O})\left(\mathrm{C}_{12} \mathrm{H}_{8} \mathrm{~N}_{2}\right)\right.} \\
\left.\left(\mathrm{CH}_{3} \mathrm{COO}\right)\left(\mathrm{H}_{2} \mathrm{O}\right)\right]_{2} \cdot 2 \mathrm{H}_{2} \mathrm{O}(\mathbf{8})\end{array}$ & N/A* & 914.5 & Non-Bent & N/A** \\
\hline $\begin{array}{l}{\left[\mathrm{UO}_{2}\left(\mathrm{C}_{12} \mathrm{H}_{8} \mathrm{~N}_{2}\right)\right.} \\
\left.\left(\mathrm{C}_{7} \mathrm{H}_{5} \mathrm{O}_{2}\right)_{2}\right](\mathbf{9})\end{array}$ & 833 & 913 & Non-Bent & $\mathrm{BA}$ \\
\hline
\end{tabular}

*-Did not feature characteristic uranyl peak in Raman spectrum

**-BA did not incorporate into the structure of 8

Looking at the $v_{3}$ asymmetric stretch values of 'bent' complexes 1-3 we observe a series of signals at $900 \mathrm{~cm}^{-1}, 888.5 \mathrm{~cm}^{-1}$, and $886.5 \mathrm{~cm}^{-1}$, respectively (Figure S14, 
Supporting Information, Table 4). The trend of increasing redshifts with greater bending contrasts with the Raman frequencies of $\mathbf{1 - 3}$ (detailed above), and additionally, the asymmetric frequencies of $\mathbf{1 - 3}$ are redshifted further from the free uranyl cation (Table 4), suggesting that deviations from linearity may have a greater impact on uranyl asymmetric stretches. Comparing the $v_{3}$ asymmetric stretch frequencies of 1-3 with their non-bent analogues 4-7, we once again note redshifts between 'bent' and 'non-bent' phases, independent of 2,4,6-trihalobenzoic acid ligand (Table 4, Figures S15 and S16, Supporting Information). The magnitude of the redshifts between 'bent' and 'non-bent' complexes are notably larger in the IR $\left(>15 \mathrm{~cm}^{-1}\right)$, which also suggests that uranyl bending may exert a greater influence on asymmetric stretching frequencies (as compared to symmetric stretches in Raman spectra).

Finally, room temperature solid-state luminescence studies were carried out on several single crystals from the bulk phases of 1-9. Uranyl materials are known to exhibit a characteristic green emission profile that results from ligand-to-metal charge transfer transitions between uranyl bonding $\left(3 \sigma_{\mathrm{u}}, 3 \sigma_{\mathrm{g}}, 2 \pi_{\mathrm{u}}\right.$, and $\left.1 \pi_{\mathrm{g}}\right)$ and non-bonding $\left(5 \mathrm{f} \delta_{\mathrm{u}}\right.$ and $\phi_{\mathrm{u}}$ ) molecular orbitals, ${ }^{22,} 66$ and for $\mathbf{2 - 7}$, characteristic emission (four to five major vibronic peaks) was observed upon excitation at $420 \mathrm{~nm}$ (Figures S17-S19, Supporting Information). The average vibronic progression of the emission bands are coupled to the Raman active vibrational modes, and for 2-7 these values were found to be in excellent agreement with measured Raman frequencies detailed in Table 4. Emission for 'bent' complex 1 was not completely resolved at room temperature, thus a similar comment cannot be made for this material. The redshifts observed when comparing 'bent' and 'non-bent' complexes in Raman and IR spectra (Table 4, Figures S11-S16, Supporting 
Information) are also noted in luminescence spectra with the largest shift between 'bent' and 'non-bent' 2,4,6-trichlorobenzoic acid complexes $\mathbf{2}$ and $\mathbf{5}$.

\section{Conclusions}

The syntheses and crystal structures of three 'bent' (1-3) and four 'non-bent' (4-7) uranyl hybrid materials containing 2,4,6-trihalobenzoic acid ligands and 1,10phenanthroline are reported along with the structures of five additional uranyl complexes that were made in the process of probing the mechanism of uranyl bending. Two of these additional complexes feature benzoic acid and phen ligands ( 8 and $\mathbf{9})$, whereas the other three complexes include 2,4,6-trichlorobenzoic acid and either 2,2,-bipyridine and 2,2'bipyridine-N,N'-dioxide (10 and 11) or 2,3,5-trichlorobenzoic acid and phen (12). The deviations from uranyl linearity displayed by complexes $\mathbf{1 - 3}$ have been compared to the small library of bent uranyl hybrid materials in the literature, and all three $\angle \mathrm{O}-\mathrm{U}-\mathrm{O}$ angles are less than $165^{\circ}$, which represents some of the most significant bending of the uranyl cation that has been observed to date. ${ }^{37,41}$ These results are particularly exciting as they demonstrate that distorting equatorial planarity and breaking uranyl linearity can be achieved without the use of complex, bulky ligands. Rather via a dual ligand strategy that combines coordination and supramolecular chemistry, facilitated by the flexibility of 1,10-phenanthroline molecules and stabilized via the creation of a ' $\pi$-pocket' by the 2,4,6-trihalobenzoic acid ligands, we were able to systematically explore structural aspects of uranyl bending. These findings were compared to results from density functional calculations and QTAIM analysis, which indicated that the bending of the uranyl unit has electrostatic origins and is energetically favorable until O-U-O angles reach approximately $162^{\circ}$, thus the uranyl bending described herein and in the recent 
examples from Hayton et al. ${ }^{37}$ and Ikeda-Ohno and colleagues ${ }^{41}$ likely represent the upper limit of uranyl bending that can be achieved via coordination chemistry pathways. Follow up studies further exploring the effects of bending the uranyl cation while simultaneously engaging the uranyl oxo atoms in non-covalent assembly are in progress and will be published in the near future. Additionally, solution state NMR studies of 'bent' species are in development.

\section{Supporting Information Available}

X-ray crystallographic files in CIF format, ORTEP figures, PXRD spectra, detailed synthetic information, Raman, IR, and luminescence spectra for complexes 1-9, single crystal XRD data for complexes 1-12, tables of selected bond lengths and bond valence summations are all available. CIFs have also been deposited at the Cambridge Crystallographic Database Centre and may be obtained from http://www.ccdc.cam.ac.uk by citing reference numbers $1582942-1582956$ for complexes $\mathbf{1 - 3}$ (RT and LT) and 4-12, respectively.

\section{Author Information}

Corresponding Author

*E-mail: cahill@gwu.edu

Phone: (202) 994-6959

Notes

The authors declare no competing financial interest.

\section{Acknowledgements}

This study was supported by the U.S. Department of Energy (DOE) — Chemical Sciences, Geosciences and Biosciences Division, Office of Basic Sciences, Office of Science, 
Heavy Elements Program, under grant number DE-FG02-05ER15736. K. P. C. would also like to acknowledge George Washington University for a Presidential Merit Fellowship award. The authors would also like to thank Dr. Karah Knope and Ms. Alyssa Adcock of Georgetown University for providing Raman microscope time and Ms. Jennifer Szymanowski for assistance with IR measurements, which were collected at the Notre Dame Energy Center.

\section{References}

1. Deifel, N. P.; Cahill, C. L., The uranyl tetrachloride anion as a tecton in the assembly of U(VI) hybrid materials. CrystEngComm 2009, 11 (12), 2739-2744.

2. Wang, K.-X.; Chen, J.-S., Extended Structures and Physicochemical Properties of Uranyl-Organic Compounds. Accounts of Chemical Research 2011, 44 (7), 531-540.

3. Baker, R. J., New Reactivity of the Uranyl(VI) Ion. Chemistry - A European Journal 2012, 18 (51), 16258-16271.

4. Thuéry, P., 2,2'-Bipyridine and 1,10-Phenanthroline as Coligands or StructureDirecting Agents in Uranyl-Organic Assemblies with Polycarboxylic Acids. European Journal of Inorganic Chemistry 2013, 2013 (26), 4563-4573.

5. Unruh, D. K.; Gojdas, K.; Libo, A.; Forbes, T. Z., Development of Metal-Organic Nanotubes Exhibiting Low-Temperature, Reversible Exchange of Confined "Ice Channels". Journal of the American Chemical Society 2013, 135 (20), 7398-7401.

6. Andrews, M. B.; Cahill, C. L., Uranyl Bearing Hybrid Materials: Synthesis, Speciation, and Solid-State Structures. Chemical Reviews 2013, 113 (2), 1121-1136.

7. Loiseau, T.; Mihalcea, I.; Henry, N.; Volkringer, C., The crystal chemistry of uranium carboxylates. Coordination Chemistry Reviews 2014, 266-267, 69-109.

8. Yang, W.; Parker, T. G.; Sun, Z.-M., Structural chemistry of uranium phosphonates. Coordination Chemistry Reviews 2015, 303, 86-109.

9. Surbella III, R. G.; Cahill, C. L., Hybrid Materials of the f-Elements Part II: The Uranyl Cation. In Handbook on the Physics and Chemistry of Rare Earths, Bünzli, J.-C. G.; Pecharsky, V. K., Eds. Elsevier: Amsterdam, 2015; Vol. 48, pp 163-285.

10. Mei, L.; Wang, C.-Z.; Wang, L.; Zhao, Y.-L.; Chai, Z.-F.; Shi, W.-Q., Halogen Bonded Three-Dimensional Uranyl-Organic Compounds with Unprecedented HalogenHalogen Interactions and Structure Diversity upon Variation of Halogen Substitution. Crystal Growth \& Design 2015, 15 (3), 1395-1406.

11. Thuery, P.; Harrowfield, J., Anchoring flexible uranyl dicarboxylate chains through stacking interactions of ancillary ligands on chiral U(VI) centres. CrystEngComm 2016, 18 (21), 3905-3918.

12. Kalaj, M.; Carter, K. P.; Cahill, C. L., Utilizing bifurcated halogen-bonding interactions with the uranyl oxo group in the assembly of a $\mathrm{UO}_{2}-3$-bromo-5-iodobenzoic acid coordination polymer. Acta Crystallographica Section B 2017, 73 (2), 234-239. 
13. Kalaj, M.; Carter, K. P.; Savchenkov, A. V.; Pyrch, M. M.; Cahill, C. L., Syntheses, Structures, and Comparisons of Heterometallic Uranyl Iodobenzoates with Monovalent Cations. Inorganic Chemistry 2017, 56 (15), 9156-9168.

14. Aakeröy, C. B.; Baldrighi, M.; Desper, J.; Metrangolo, P.; Resnati, G., Supramolecular Hierarchy among Halogen-Bond Donors. Chemistry - A European Journal 2013, 19 (48), 16240-16247.

15. Surbella III, R. G.; Andrews, M. B.; Cahill, C. L., Self-assembly of $\left[\mathrm{UO}_{2} \mathrm{X}_{4}\right]^{2-}$ $(\mathrm{X}=\mathrm{Cl}, \mathrm{Br})$ dianions with $\gamma$ substituted pyridinium cations: Structural systematics and fluorescence properties. Journal of Solid State Chemistry 2016, 236, 257-271.

16. Surbella III, R. G.; Ducati, L. C.; Pellegrini, K. L.; McNamara, B. K.; Autschbach, J.; Schwantes, J. M.; Cahill, C. L., Transuranic Hybrid Materials: Crystallographic and Computational Metrics of Supramolecular Assembly. Journal of the American Chemical Society 2017, 139 (31), 10843-10855.

17. Carter, K. P.; Cahill, C. L., Combining coordination and supramolecular chemistry to explore uranyl assembly in the solid state. Inorganic Chemistry Frontiers 2015, 2 (2), 141-156.

18. Carter, K. P.; Kalaj, M.; Cahill, C. L., Probing the Influence of N-Donor Capping Ligands on Supramolecular Assembly in Molecular Uranyl Materials. European Journal of Inorganic Chemistry 2016, 2016 (1), 126-137.

19. Carter, K. P.; Kalaj, M.; Cahill, C. L., Harnessing uranyl oxo atoms via halogen bonding interactions in molecular uranyl materials featuring 2,5-diiodobenzoic acid and $\mathrm{N}$-donor capping ligands. Inorganic Chemistry Frontiers 2017, 4 (1), 65-78.

20. Carter, K. P.; Kalaj, M.; III, R. G. S.; Ducati, L. C.; Autschbach, J.; Cahill, C. L., Engaging the terminal: promoting halogen bonding interactions with uranyl oxo atoms. Chemistry - A European Journal 2017, 23, 15355-15369.

21. Kalaj, M.; Carter, K. P.; Cahill, C. L., Isolating Equatorial and Oxo Based Influences on Uranyl Vibrational Spectroscopy in a Family of Hybrid Materials Featuring Halogen Bonding Interactions with Uranyl Oxo Atoms. European Journal of Inorganic Chemistry 2017, 2017, 4702-4713.

22. Denning, R. G., Electronic Structure and Bonding in Actinyl Ions and their Analogs. The Journal of Physical Chemistry A 2007, 111 (20), 4125-4143.

23. Schreckenbach, G.; Hay, P. J.; Martin, R. L., Theoretical Study of Stable Trans and $\mathrm{Cis}$ Isomers in $\left[\mathrm{UO}_{2}(\mathrm{OH})_{4}\right]^{2-}$ Using Relativistic Density Functional Theory. Inorganic Chemistry 1998, 37 (17), 4442-4451.

24. Burns, P. C., $\mathrm{U}^{6+}$ Minerals and Inorganic Compounds: Insights Into an Expanded Structural Hierarchy of Crystal Structures. The Canadian Mineralogist 2005, 43 (6), 1839-1894.

25. Fortier, S.; Hayton, T. W., Oxo ligand functionalization in the uranyl ion $\left(\mathrm{UO}_{2}{ }^{2+}\right)$. Coordination Chemistry Reviews 2010, 254 (3-4), 197-214.

26. Arnold, P. L.; Pécharman, A.-F.; Hollis, E.; Yahia, A.; Maron, L.; Parsons, S.; Love, J. B., Uranyl oxo activation and functionalization by metal cation coordination. Nature Chemistry 2010, 2 (12), 1056-1061.

27. Arnold, P. L.; Pécharman, A.-F.; Lord, R. M.; Jones, G. M.; Hollis, E.; Nichol, G. S.; Maron, L.; Fang, J.; Davin, T.; Love, J. B., Control of Oxo-Group Functionalization and Reduction of the Uranyl Ion. Inorganic Chemistry 2015, 54 (7), 3702-3710. 
28. Seaman, L. A.; Pedrick, E. A.; Wu, G.; Hayton, T. W., Promoting oxo functionalization in the uranyl ion by ligation to ketimides. Journal of Organometallic Chemistry 2017 https://doi.org/10.1016/j.jorganchem.2017.08.007.

29. Sessler, J. L.; Seidel, D.; Vivian, A. E.; Lynch, V.; Scott, B. L.; Keogh, D. W., Hexaphyrin(1.0.1.0.0.0): An Expanded Porphyrin Ligand for the Actinide Cations Uranyl $\left(\mathrm{UO}_{2}{ }^{2+}\right)$ and Neptunyl $\left(\mathrm{NpO}_{2}{ }^{+}\right)$. Angewandte Chemie International Edition 2001, 40 (3), 591-594.

30. Berthet, J.-C.; Nierlich, M.; Ephritikhine, M., A novel coordination geometry for the uranyl ion. Rhombohedral uranium environment in $\left[\mathrm{UO}_{2}(\mathrm{OTf})_{2}(\mathrm{bpy})_{2}\right]$ and $\left.\left[\mathrm{UO}_{2} \text { (phen) }\right)_{3}\right][\mathrm{OTf}]_{2}$. Chemical Communications 2003, (14), 1660-1661.

31. Copping, R.; Jeon, B.; Pemmaraju, C. D.; Wang, S.; Teat, S. J.; Janousch, M.; Tyliszczak, T.; Canning, A.; Grønbech-Jensen, N.; Prendergast, D.; Shuh, D. K., Toward Equatorial Planarity about Uranyl: Synthesis and Structure of Tridentate Nitrogen-Donor $\left\{\mathrm{UO}_{2}\right\}^{2+}$ Complexes. Inorganic Chemistry 2014, 53 (5), 2506-2515.

32. Pemmaraju, C. D.; Copping, R.; Smiles, D. E.; Shuh, D. K.; Grønbech-Jensen, N.; Prendergast, D.; Canning, A., Coordination Characteristics of Uranyl BBP Complexes: Insights from an Electronic Structure Analysis. ACS Omega 2017, 2 (3), 1055-1062.

33. Wilkerson, M. P.; Burns, C. J.; Morris, D. E.; Paine, R. T.; Scott, B. L., Steric Control of Substituted Phenoxide Ligands on Product Structures of Uranyl Aryloxide Complexes. Inorganic Chemistry 2002, 41 (12), 3110-3120.

34. Maynadie, J.; Berthet, J.-C.; Thuery, P.; Ephritikhine, M., The first cyclopentadienyl complex of uranyl. Chemical Communications 2007, (5), 486-488.

35. Berthet, J.-C.; Thuéry, P.; Dognon, J.-P.; Guillaneux, D.; Ephritikhine, M., Sterically Congested Uranyl Complexes with Seven-Coordination of the UO2 Unit: the Peculiar Ligation Mode of Nitrate in $\left[\mathrm{UO}_{2}\left(\mathrm{NO}_{3}\right)_{2}(\mathrm{Rbtp})\right]$ Complexes. Inorganic Chemistry 2008, 47 (15), 6850-6862.

36. Szigethy, G.; Raymond, K. N., Hexadentate Terephthalamide(bishydroxypyridinone) Ligands for Uranyl Chelation: Structural and Thermodynamic Consequences of Ligand Variation. Journal of the American Chemical Society 2011, 133 (20), 7942-7956.

37. Pedrick, E. A.; Schultz, J. W.; Wu, G.; Mirica, L. M.; Hayton, T. W., Perturbation of the $\mathrm{O}-\mathrm{U}-\mathrm{O}$ Angle in Uranyl by Coordination to a 12-Membered Macrocycle. Inorganic Chemistry 2016, 55 (11), 5693-5701.

38. Kiernicki, J. J.; Cladis, D. P.; Fanwick, P. E.; Zeller, M.; Bart, S. C., Synthesis, Characterization, and Stoichiometric U-O Bond Scission in Uranyl Species Supported by Pyridine(diimine) Ligand Radicals. Journal of the American Chemical Society 2015, 137 (34), 11115-11125.

39. Anderson, N. H.; Xie, J.; Ray, D.; Zeller, M.; Gagliardi, L.; Bart, S. C., Elucidating bonding preferences in tetrakis(imido)uranate(VI) dianions. Nature Chemistry 2017, 9 (9), 850-855.

40. Hayton, T. W., Understanding the origins of $\mathrm{O}_{\mathrm{yl}}-\mathrm{U}-\mathrm{O}_{\mathrm{yl}}$ bending in the uranyl $\left(\mathrm{UO}_{2}{ }^{2+}\right)$ ion. Dalton Transactions 2018 10.1039/C7DT04123C.

41. Schöne, S.; Radoske, T.; März, J.; Stumpf, T.; Patzschke, M.; Ikeda-Ohno, A., $\left.\left[\mathrm{UO}_{2} \mathrm{Cl}_{2} \text { (phen) }\right)_{2}\right]$, a Simple Uranium(VI) Compound with a Significantly Bent Uranyl Unit (phen=1,10-phenanthroline). Chemistry - A European Journal 2017, 23, 1357413578. 
42. SAINT, Bruker AXS Inc.: Madison, Wisconsin, USA, 2007.

43. APEXII Software Suite, version 2.3; Bruker AXS Inc. : Madison, Wisconsin, USA, 2008.

44. Krause, L.; Herbst-Irmer, R.; Sheldrick, G. M.; Stalke, D., Comparison of silver and molybdenum microfocus X-ray sources for single-crystal structure determination. Journal of Applied Crystallography 2015, 48 (1), 3-10.

45. Altomare, A.; Cascarano, G.; Giacovazzo, C.; Guagliardi, A.; Burla, M. C.; Polidori, G.; Camalli, M., SIR92 - a program for automatic solution of crystal structures by direct methods. Journal of Applied Crystallography 1994, 27 (3), 435-435.

46. Sheldrick, G., Crystal structure refinement with SHELXL. Acta Crystallographica Section C 2015, 71 (1), 3-8.

47. Farrugia, L., WinGX and ORTEP for Windows: an update. Journal of Applied Crystallography 2012, 45 (4), 849-854.

48. CrystalMaker, version 8.2.2; Crystal Maker Software Limited: Bicester, England, 2009.

49. Putz, H.; Brandenburg, K. Match! - Phase Identification from Powder Diffraction Crystal Impact: Bonn, Germany, 2015.

50. Ahlrichs, R.; Bär, M.; Häser, M.; Horn, H.; Kölmel, C., Electronic structure calculations on workstation computers: The program system turbomole. Chemical Physics Letters 1989, 162 (3), 165-169.

51. Weigend, F.; Ahlrichs, R., Balanced basis sets of split valence, triple zeta valence and quadruple zeta valence quality for $\mathrm{H}$ to $\mathrm{Rn}$ : Design and assessment of accuracy. Physical Chemistry Chemical Physics 2005, 7 (18), 3297-3305.

52. Küchle, W.; Dolg, M.; Stoll, H.; Preuss, H., Energy-adjusted pseudopotentials for the actinides. Parameter sets and test calculations for thorium and thorium monoxide. The Journal of Chemical Physics 1994, 100 (10), 7535-7542.

53. Di Pietro, P.; Kerridge, A., U-O $\mathrm{O}_{\mathrm{yl}}$ Stretching Vibrations as a Quantitative Measure of the Equatorial Bond Covalency in Uranyl Complexes: A Quantum-Chemical Investigation. Inorganic Chemistry 2016, 55 (2), 573-583.

54. Di Pietro, P.; Kerridge, A., Assessing covalency in equatorial U-N bonds: density based measures of bonding in BTP and isoamethyrin complexes of uranyl. Physical Chemistry Chemical Physics 2016, 18 (25), 16830-16839.

55. Bader, R. F. W., Atoms in Molecules: A Quantum Theory. Oxford University Press: Oxford, UK, 1990.

56. Keith, T. A. AIMA11, version 13.11.04; TK Gristmall Software: Overland Park, KS, 2014.

57. Groom, C. R.; Bruno, I. J.; Lightfoot, M. P.; Ward, S. C., The Cambridge Structural Database. Acta Crystallographica Section B 2016, 72 (2), 171-179.

58. Janiak, C., A critical account on $\pi-\pi$ stacking in metal complexes with aromatic nitrogen-containing ligands. Journal of the Chemical Society, Dalton Transactions 2000, (21), 3885-3896.

59. Sonnenberg, J. L.; Hay, P. J.; Martin, R. L.; Bursten, B. E., Theoretical Investigations of Uranyl-Ligand Bonding: Four- and Five-Coordinate Uranyl Cyanide, Isocyanide, Carbonyl, and Hydroxide Complexes. Inorganic Chemistry 2005, 44 (7), 2255-2262. 
60. Iché-Tarrat, N.; Barros, N.; Marsden, C. J.; Maron, L., Linear Uranium Complexes $\mathrm{X}_{2} \mathrm{UL}_{5}$ with $\mathrm{L}=\mathrm{Cyanide}$, Isocyanate: DFT Evidence for Similarities between Uranyl $(\mathrm{X}=\mathrm{O})$ and Uranocene $(\mathrm{X}=\mathrm{Cp})$ Derivatives. Chemistry - A European Journal 2008, 14 (7), 2093-2099.

61. Fillaux, C.; Guillaumont, D.; Berthet, J.-C.; Copping, R.; Shuh, D. K.; Tyliszczak, T.; Auwer, C. D., Investigating the electronic structure and bonding in uranyl compounds by combining NEXAFS spectroscopy and quantum chemistry. Physical Chemistry Chemical Physics 2010, 12 (42), 14253-14262.

62. Herzberg, G., Infrared and Raman Spectra of Polyatomic Molecules. D. Van Nostrand Company, Inc.: New York, NY, 1946.

63. Nakamoto, K., Infrared and Raman Spectra of Inorganic and Coordination Compounds Part A: Theory and Applications in Inorganic Chemistry. 5th ed.; John Wiley \& Sons, Inc. : New York, NY, 1997.

64. Jones, L. H.; Penneman, R. A., Infrared Spectra and Structure of Uranyl and Transuranium (V) and (VI) Ions in Aqueous Perchloric Acid Solution. The Journal of Chemical Physics 1953, 21 (3), 542-544.

65. Kerridge, A., Quantification of f-element covalency through analysis of the electron density: insights from simulation. Chemical Communications 2017, 53 (50), 6685-6695.

66. Natrajan, L. S., Developments in the photophysics and photochemistry of actinide ions and their coordination compounds. Coordination Chemistry Reviews 2012, 256 (1516), 1583-1603.

\section{For Table of Contents Only}

Three uranyl complexes featuring deviations from linearity of more than $15^{\circ}$ have been synthesized and their structural, supramolecular, spectroscopic, and computational properties have been comprehensively explored. Additionally, these findings are put into context via direct comparison with twelve 'non-bent' uranyl complexes that were also prepared as part of this study. Presented is a strategy and general approach to the manipulation of the $\mathrm{O}=\mathrm{U}=\mathrm{O}$ bond angle via a combination of simple coordination chemistry and promoted supramolecular interactions. 

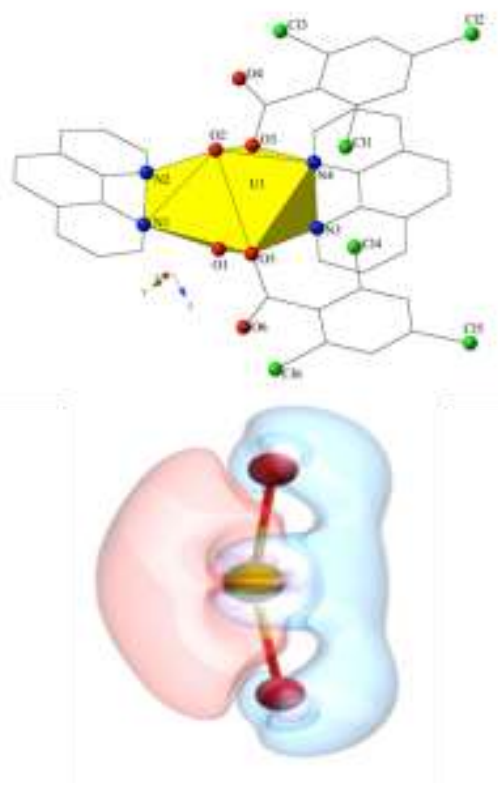